\title{
Thermodynamic constraints on fiber diameter, neural activity, and brain temperature Jan Karbowski ${ }^{1,2}$
}

Address: ${ }^{1}$ Caltech, Division of Biology 216-76, Pasadena, CA 91125, USA and ${ }^{2}$ Institute of Biocybernetics and Biomedical Engineering, Polish Academy of Sciences, 02-109 Warsaw, Poland

Email: Jan Karbowski - jkarb@its.caltech.edu

from Eighteenth Annual Computational Neuroscience Meeting: CNS*2009

Berlin, Germany. 18-23 July 2009

Published: 13 July 2009

BMC Neuroscience 2009, I0(Suppl I):P6 doi:I0.II86/I47I-2202-I0-SI-P6

This abstract is available from: http://www.biomedcentral.com/I47I-2202/I0/SI/P6

(c) 2009 Karbowski; licensee BioMed Central Ltd.

There have been suggestions that heat caused by cerebral metabolic activity may constrain mammalian brain evolution, architecture, and function [1-4]. This study [5] investigates physical limits on brain wiring and corresponding changes in brain temperature that are imposed by thermodynamics of heat balance determined mainly by $\mathrm{Na} / \mathrm{K}$ ATPase, cerebral blood flow, and heat conduction. It is found that even moderate firing rates cause significant intracellular Na build-up, and the ATP consumption rate associated with pumping out these ions grows nonlinearly with frequency. Surprisingly, the power dissipated by the $\mathrm{Na} / \mathrm{K}$ pump depends biphasically on frequency, which can lead to the biphasic dependence of brain temperature on frequency as well. Both the total power of sodium pumps and brain temperature diverge for very small fiber diameters, indicating that too thin fibers are not beneficial for thermal balance. For very small brains blood flow is not a sufficient cooling mechanism deep in the brain. The theoretical lower bound on fiber diameter above which brain temperature is in the operational regime is strongly frequency dependent but finite due to synaptic depression. For normal neurophysiological conditions this bound is at least an order of magnitude smaller than average values of empirical fiber diameters, suggesting that mammalian brains operate in the thermodynamically safe regime. Analytical formulas presented can be used to estimate average firing rates in mammals, and relate their changes to changes in brain temperature, which can have important practical applications. In general, activity in larger brains is found to be slower than in smaller brains.

\section{References}

I. Aiello LC, Wheeler P: The expensive-tissue hypothesis: the brain and the digestive-system in human and primate evolution. Curr Anthrop 1995, 36: 199-22I.

2. Attwell $D$, Laughlin SB: An energy budget for signaling in the gray matter of the brain. J Cereb Blood Flow Metabol 200I, 21: I I33-II 45.

3. Faisal AA, White JA, Laughlin SB: Ion-channel noise places limits on the miniaturization of the brain's wiring. Curr Biol 2005, I5: I |43-1 | 49 .

4. Karbowski J: Global and regional brain metabolic scaling and its functional consequences. BMC Biology 2007, 5: 18 .

5. Karbowski J: Thermodynamic constraints on neural dimensions, firing rates, brain size and temperature. J Comput Neurosci 2009 in press. 